\title{
Genome-wide association studies for genetic effects that change during lactation in dairy cattle
}

\author{
Haibo Lu and Henk Bovenhuis* \\ Animal Breeding and Genomics, Wageningen University and Research, PO Box 338, $6700 \mathrm{AH}$, Wageningen, the Netherlands
}

\begin{abstract}
Genetic effects on milk production traits in dairy cattle might change during lactation. However, most genome-wide association studies (GWAS) for milk production traits assume that genetic effects are constant during lactation. This assumption might lead to missing these quantitative trait loci (QTL) whose effects change during lactation. This study aimed to screen the whole genome specifically for QTL whose effects change during lactation. For this purpose, 4 different GWAS approaches were performed using testday milk protein content records: (1) separate GWAS for specific lactation stages, (2) GWAS for estimated Wilmink lactation curve parameters, (3) a GWAS using a repeatability model where SNP effects are assumed constant during lactation, and (4) a GWAS for genotype by lactation stage interaction using a repeatability model and accounting for changing genetic effects during lactation. Separate GWAS for specific lactation stages suggested that the detection power greatly differs between lactation stages and that genetic effects of some QTL change during lactation. The GWAS for estimated Wilmink lactation curve parameters detected many chromosomal regions for Wilmink parameter $a$ (protein content level), whereas 2 regions for Wilmink parameter $b$ (decrease in protein content toward nadir) and no regions for Wilmink parameter $c$ (increase in protein content after nadir) were detected. Twenty chromosomal regions were detected with effects on milk protein content; however, there was no evidence that their effects changed during lactation. For 5 chromosomal regions located on chromosomes $3,9,10,14$, and 27 , significant evidence was observed for a genotype by lactation stage interaction and thus their effects on milk protein content changed during lactation. Three of these 5 regions were only identified using a GWAS for genotype by lactation stage interaction. Our study demonstrated that GWAS for genotype by lactation
\end{abstract}

Received November 14, 2018.

Accepted April 4, 2019.

*Corresponding author: henk.bovenhuis@wur.nl stage interaction offers new possibilities to identify QTL involved in milk protein content. The performed approaches can be applied to other milk production traits. Identification of QTL whose genetic effects change during lactation will help elucidate the genetic and biological background of milk production.

Key words: genome-wide association studies, genetic effect, longitudinal trait, genotype by lactation stage interaction

\section{INTRODUCTION}

Quantitative genetic studies have shown that the additive genetic variance for milk production traits changes during lactation (e.g., Jakobsen et al., 2002; Druet et al., 2005) and genetic correlations between milk production traits in early and late lactation differ from unity (e.g., Druet et al., 2003; Bastin et al., 2011). Furthermore, for the diacylglycerol O-acyltransferase 1 (DGAT1) K232A polymorphism it has been shown that its effect on milk production traits is not constant during lactation (e.g., Strucken et al., 2011; Szyda et al., 2014; Bovenhuis et al., 2015). In addition, results from gene expression studies show that the expression of several genes involved in milk production changes during lactation (e.g., Bionaz and Loor, 2011; Wickramasinghe et al., 2012). Therefore, genetic effects on milk production traits might change during lactation. However, genome-wide association studies (GWAS) for milk production traits are mainly based on 305-d lactation records, which are summed or average test-day milk production records (e.g., Jiang et al., 2010; Cole et al., 2011). These studies detect QTL based on their average genetic effects during the whole lactation and assume that genetic effects of QTL related to milk production traits are constant. In a GWAS using models assuming constant genetic effects during lactation, QTL whose genetic effects change during lactation might not be detected (Lund et al., 2008; Ning et al., 2018).

Only a few studies specifically performed genomewide screens for QTL whose genetic effects change during lactation (Strucken et al., 2012a; Macciotta et al., 2015). These GWAS were performed based on 
estimated lactation curve parameters or principal components and used relatively small data sets (less than 400 cows). Alternatively, screening the whole genome specifically for regions showing genotype by lactation stage interaction has not previously been carried out.

The objective of this study was to screen the whole genome for genetic effects that change during lactation. For this purpose we performed 4 GWAS approaches using test-day milk protein content in Dutch first parity Holstein cows: (1) separate GWAS for specific lactation stages; (2) GWAS for estimated Wilmink lactation curve parameters; (3) a GWAS using a repeatability model where SNP effects are assumed constant during lactation; and (4) a GWAS for genotype by lactation stage interaction using a repeatability model and accounting for changing genetic effects during lactation. This study will provide insight in differences between the 4 approaches and might lead to the detection of new QTL that would not have been detected when using models assuming genetic effects are constant. The results of this study are expected to further elucidate the genetic and biological background of milk protein content.

\section{MATERIALS AND METHODS}

\section{Phenotypes and Genotypes}

For this study, data on 1,829 Dutch Holstein firstparity cows were available. These cows are housed on 398 commercial herds in the Netherlands with at least 3 cows per herd. All cows were at least $87.5 \%$ HolsteinFriesian and descended from 5 proven bulls (98 to 196 daughters per sire), 50 test bulls ( 8 to 23 daughters per sire), and 15 other proven bulls ( 1 to 25 daughters per sire). Cows were milked twice daily and milk protein content was determined as part of routine milk recording using infrared spectroscopy (MilkoScan FT 6000, Foss Electric, Hillerød, Denmark) at the milk control station (Qlip, Zutphen, the Netherlands). The lactation was truncated at $390 \mathrm{~d}$, each cow on average had 10.7 test-day records, and the total number of test-day records was 19,593. Average milk protein content was $3.50 \%$ and the standard deviation was $0.31 \%$.

The DNA was isolated from blood samples and cows were genotyped using a customized 50k SNP chip (CRV, Cooperative Cattle Improvement Organization, Arnhem, the Netherlands) with the Infinium assay (Illumina, San Diego, CA). The SNP sequence were mapped using BLAST (http://www.ncbi.nlm.nih.gov/ blast) and bovine genome assembly Btau 4.0 (Liu et al., 2009). In total, 1,868 cows were genotyped and 1,800 cows had both genotypes and test-day milk protein content records.

\section{GWAS Approaches}

If QTL effects change during lactation, separate GWAS for specific lactation stages might give different results. The GWAS signals might be strong during some parts of the lactation and weak or absent during other lactation stages. Therefore, in the first GWAS approach, separate genome-wide associations were performed for specific lactation stages. For this purpose the lactation was divided in 26 lactation stages of $15 \mathrm{~d}$ each. The average number of test-day records for each lactation stage was 754 . The GWAS were performed based on data from 2 consecutive lactation stage classes (e.g., lactation stages 1 and 2, 3 and 4, and so on). In this way most of the cows had at least one testday record in each of the separate GWAS. Because the number of records per lactation stage decreased toward the end of lactation, data from lactation stages 21 to 26 were combined for the last GWAS. Combining lactation stage classes might in some cases result in multiple test-day records per cow in a GWAS data set. In that case the first test-day record of a cow was removed. The number of records in each lactation stage and each separate GWAS data set are shown in Supplemental Table S1 (https://doi.org/10.3168/jds.2018-15994). The GWAS for specific lactation stages were performed using model [1]:

$$
\begin{aligned}
y_{j k l m n o}= & \mu+b_{1} \times \text { afc }_{\text {jklmno }}+\text { season }_{j}+\text { scode }_{k}+\text { lact }_{l} \\
& +S N P_{m}+\text { HTD }_{n}+\text { animal }_{o}+e_{j k l m n o},
\end{aligned}
$$

where $y_{j k l m n o}$ is test-day milk protein content; $\mu$ is the overall mean; $a f c_{j k l m n o}$ is a covariate describing the effect of age at first calving with regression coefficient $b_{1}$; season $_{j}$ is the fixed effect of calving season (June-August 2004, September-November 2004, and December 2004-February 2005); scode $_{k}$ is the fixed effect accounting for possible differences in genetic level between daughters of proven bulls, test bulls, and other proven bulls; lact $_{l}$ is the fixed effect of lactation stage (26 classes of $15 \mathrm{~d}$ each); $S N P_{m}$ is the fixed effect of SNP genotype, modeled as a class variable; $H T D_{n}$ is the random effect of herd-test-day, which was assumed to be distributed as $N\left(\mathbf{0}, \mathbf{I} \sigma_{H T D}^{2}\right)$, where $\mathbf{I}$ is the identity matrix and $\sigma_{H T D}^{2}$ is the herd-test-day variance; animal $_{o}$ is the random additive genetic effect of the individual and was assumed to be distributed as $N\left(\mathbf{0}, \mathbf{A} \sigma_{a}^{2}\right)$, where $\mathbf{A}$ is the additive genetic relationships matrix constructed based on 14,062 animals and $\sigma_{a}^{2}$ is additive genetic variance; and $e_{j k l m n o}$ is the random residual and was assumed to be distributed as $N\left(\mathbf{0}, \mathbf{I} \sigma_{e}^{2}\right)$, where $\mathbf{I}$ is the identity matrix and $\sigma_{e}^{2}$ is residual variance. Pedigree of 
the animals was traced back to 5 generations and provided by the Dutch herdbook (CRV, Arnhem, the Netherlands). Model [1] accounts for a lactation stage effect $\left(\right.$ lact $t_{l}$ ) because each separate GWAS analyzed test-day records from at least 2 different lactation stage classes.

Genome-wide association studies based on estimated lactation curve parameters were performed (Strucken et al., 2012a). To be able to compare our results with these GWAS, we performed the second GWAS approach. In these analyses, we first fitted a Wilmink lactation curve (Wilmink, 1987) to the test-day records of each cow using the following model:

$$
y_{i}=a+b \times \exp ^{-0.05 \times D I M_{i}}+c \times D I M_{i} \times e_{i},
$$

where $y_{i}$ is test-day milk protein content; $D I M_{i}$ is days in milk; parameter $a$ represents the milk protein content level; parameter $b$ represents the decrease in protein content toward nadir; and parameter $c$ represents the increase in protein content after nadir. Lactation curve parameters were estimated using the Procedure NLIN in SAS (SAS Institute Inc., 1999). Subsequently GWAS for estimated lactation curve parameters, as proposed by Strucken et al. (2012a), were performed using the following model:

$$
\begin{gathered}
y_{j k m n o}=\mu+b_{1} \times \text { afc }_{j k m n o}+\text { season }_{j}+\text { scode }_{k} \\
+ \text { SNP }_{m}+\text { Herd }_{n}+\text { animal }_{o}+e_{j k m n o}
\end{gathered}
$$

where $y_{j k m n o}$ are estimated lactation curve parameters $a$, $b$, or $c$, and $\operatorname{Herd}_{n}$ is the random effect of herd, which was assumed to be distributed as $N\left(\mathbf{0}, \mathbf{I} \sigma_{\text {Herd }}^{2}\right)$, where $\sigma_{\text {Herd }}^{2}$ is the herd variance. The other model terms are as described for model [1].

A GWAS using a model that assumes that genetic effects are constant during lactation might not be able to detect QTL whose genetic effects change during lactation (Lund et al., 2008; Ning et al., 2018). To investigate this hypothesis, we performed a third GWAS approach using all test-day records and the following repeatability model that assumes that SNP effects are constant throughout the lactation:

$$
\begin{gathered}
y_{j k l m n o p}=\mu+b_{1} \times \text { af }_{\text {jklmnop }}+\text { season }_{j}+\text { scode }_{k}+\text { lact }_{l} \\
+S N P_{m}+\operatorname{HTD}_{n}+\text { animal }_{o}+\text { pe }_{p}+e_{j k l m n o p},
\end{gathered}
$$

where $p e_{p}$ is the permanent environmental effect that was assumed to be distributed as $N\left(\mathbf{0}, \mathbf{I} \sigma_{p e}^{2}\right)$, where $\mathbf{I}$ is the identity matrix and $\sigma_{p e}^{2}$ is permanent environmental variance. Other model terms are as described for model
[1], and lactation stage (lact l ) has 26 classes in this analysis.

Finally, we performed a fourth GWAS approach to specifically search for QTL whose effects change throughout lactation (i.e., SNP that show a significant genotype by lactation stage interaction). For this purpose, model [4] was extended with a SNP by lactation stage interaction term $(S N P \times \text { lact })_{l m}$ :

$$
\begin{gathered}
y_{j k l m n o p}=\mu+b_{1} \times \text { af }_{j_{\text {klmnop }}}+\text { season }_{j}+\text { scode }_{k}+\text { lact }_{l} \\
+S N P_{m}+(S N P \times \text { lact })_{l m}+H T D_{n}+\text { animal }_{o} \\
+e_{p}+e_{j k l m n o p},
\end{gathered}
$$

where model terms are as described for model [1] and lactation stage $\left(\right.$ lact $\left._{l}\right)$ has 26 classes in this analysis. For SNP that showed a significant SNP by lactation stage interaction, the effects during the course of lactation were estimated using a model including the SNP by lactation stage interaction but without the main effects of SNP and lactation stage:

$$
\begin{gathered}
y_{j k l m n o p}=\mu+b_{1} \times \text { afc }_{\text {jklmnop }}+\text { season }_{j}+\text { scode }_{k} \\
+(S N P \times \text { lact })_{l m}+\text { HTD }_{n}+\text { animal }_{o} \\
+ \text { pe } e_{p}+e_{j k l m n o p},
\end{gathered}
$$

where model terms are as described for model [1] and lactation stage class $\left(\right.$ lact $\left._{l}\right)$ has 26 classes. A $t$-test was used to test the significance of the difference between any of 2 SNP genotypes within each lactation stage. If the $P$-value for the possible comparisons between any of 2 SNP genotypes was smaller than 0.001 , the SNP effect within that lactation stage was considered significant.

To test SNP by lactation stage interaction, any SNP genotype class in each lactation stage class needs to have a sufficiently large number of test-day records. The SNP were not included in the GWAS if a genotype class contained less than 10 test-day records in any of the lactation stage classes. After this restriction, 30,348 SNP remained and the same SNP were used in the different GWAS approaches. All GWAS were performed in ASReml 4 (Gilmour et al., 2006).

\section{Significance Threshold}

The significance of SNP effects in GWAS approach 1 (separate lactation stages), GWAS approach 2 (Wilmink lactation curve parameters), GWAS approach 3 (repeatability model), and the SNP by lactation stage interaction effect in GWAS approach 4 were tested using the Wald F-test statistic. Possible inflation of the test 
statistic was inspected based on quantile-quantile plots where the observed $-\log _{10}(P$-value $)$ was plotted against the expected $-\log _{10}(P$-value $)$. The genome-wide significance threshold for the SNP effects was based on false discovery rate (FDR). The FDR was calculated using the R package "qvalue" (Storey and Tibshirani, 2003) and FDR $<0.01$ was considered significant. Previous GWAS for SNP by environment interaction observed a strong inflation of the test statistic for the interaction term (e.g., Voorman et al., 2011; Marigorta and Gibson, 2014). When the distribution of the test statistic under null hypothesis is unambiguous, permutation is a powerful strategy to estimate the significance threshold (Churchill and Doerge, 1994; Doerge and Churchill, 1996). Therefore, the genome-wide significance threshold for the SNP by lactation stage interaction effect was not based on FDR but determined using permutation. In each permutation, all 30,348 SNP of an animal were simultaneously assigned to a randomly selected other animal. Subsequently a GWAS was performed using the permuted genotypes. For each permutation the smallest genome-wide $P$-value of the SNP by lactation stage interaction term was stored. Permutation was repeated 100 times to determine the $1 \%$ significance threshold for the interaction term.

\section{RESULTS}

The SNP with the highest $-\log _{10}(P$-value $)$ for significant chromosomal regions (lead SNP) identified in the different GWAS approaches are in Table 1. Different chromosomal regions on the same chromosome are differentiated by letters.

\section{Separate GWAS for Specific Lactation Stages}

Manhattan plots of separate GWAS for specific lactation stages are shown in Figure 1. Results are presented for early lactation (lactation stages 1 and 2, Figure 1A), mid lactation (lactation stages 13 and 14, Figure 1B), and late lactation (lactation stages 21 to 26, Figure 1C). Manhattan plots of separate GWAS for other lactation stages are shown in Supplemental Figure S1 (https:// doi.org/10.3168/jds.2018-15994). Figure 1 and Table 1 show large differences between lactation stages in the number of detected chromosomal regions. In early lactation, only one region on BTA 6 significantly affected milk protein content. In mid lactation, significant associations were detected on BTA 4, 5, 6, 10a, 10c, 14a, 15a, 20, 24, and 26. In late lactation, significant associations were detected on BTA $6,10 \mathrm{~b}, 14 \mathrm{a}$, and $16 \mathrm{a}$. The region on BTA 6, which contains the casein gene cluster, was the only region that showed significant associations in all separate GWAS for specific lactation stages. The region on BTA $14 \mathrm{a}$, which contains the DGAT1, did not show significant associations in early lactation and the significance of the GWAS signal showed large changes as lactation progressed (Table 1). Except BTA 6 and 14a, regions on BTA 4, 5, 10a, 10c, 15a, 20, 24, and 26 showed significant effects in mid lactation but no significant effects in early and late lactation. The region on BTA 10b and 16a showed significant associations in late lactation, but no associations were detected in early and mid lactation. These differences between lactation stages in the number of detected chromosomal regions and in their significance suggest that genetic effects of some QTL change during lactation.

\section{GWAS for Wilmink Lactation Curve Parameters}

Manhattan plots of GWAS for the 3 Wilmink lactation curve parameters are shown in Figure 2. For parameter $a$, representing the milk protein content level during lactation, significant SNP were detected on BTA 1, 6, 8b, 9a, 14a, 15b, 16b, 20, 23, and 26 (Figure 2A). The strongest GWAS signals for parameter $a$ were detected on BTA $6,14 \mathrm{a}$, and 20. For parameter $b$, which represents the decrease in protein content toward nadir, significant effects were detected on BTA 14a and 18 (Figure 2B). For parameter $c$, which represents the increase in protein content after nadir, no significant QTL were detected (Figure 2C).

\section{GWAS Based on the Repeatability Model}

The Manhattan plot for the GWAS using a repeatability model and assuming SNP effects are constant during lactation is shown in Figure 3. Significant chromosomal regions were detected on BTA 4, 6, 7, 8a, 10c, 11, 14a, 14b, 15a, 15b, 16a, 20, and 26. Strong GWAS signals were found on BTA $6,14 \mathrm{a}, 15 \mathrm{a}, 15 \mathrm{~b}$, and 20 , as $90 \%$ of the SNP that passed the significance threshold were clustered in these chromosomal regions.

\section{GWAS for SNP by Lactation Stage Interaction}

The Wald $F$-statistic for the SNP by lactation stage interaction effect showed a strong inflation, which is illustrated in the quantile-quantile plot (Supplemental Figure S2; https://doi.org/10.3168/jds.2018-15994). To determine the appropriate threshold for the SNP by lactation stage, interaction term permutation was performed. Based on 100 permutations, the $1 \%$ genome-wide significance threshold was estimated to be $-\log _{10}(P$-value $)=18.6$.

The Manhattan plot for the SNP by lactation stage interaction effect is shown in Figure 4. Significant SNP were detected on BTA 3, 9b, 10b, 14a, and 27. Estimat- 


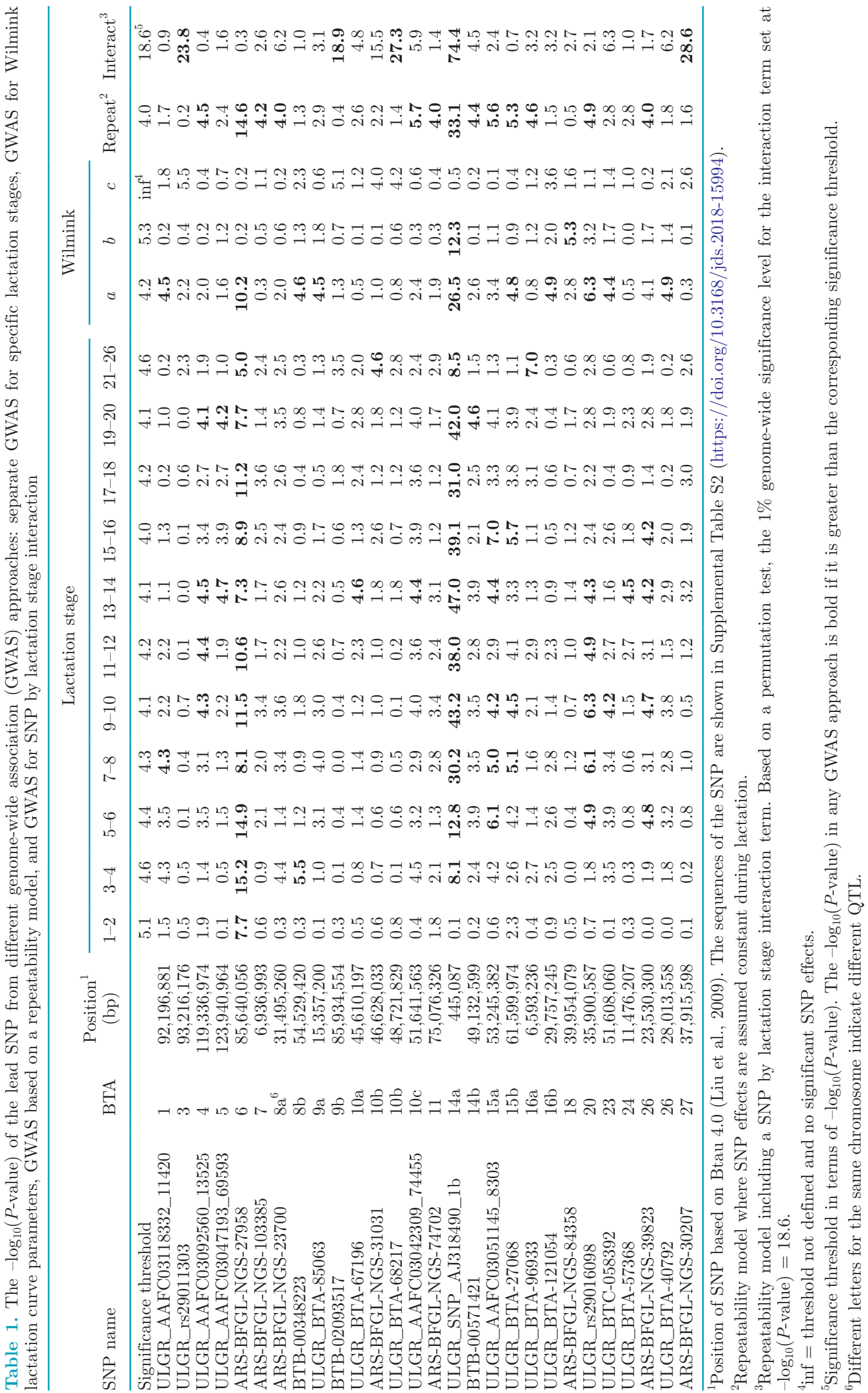


A

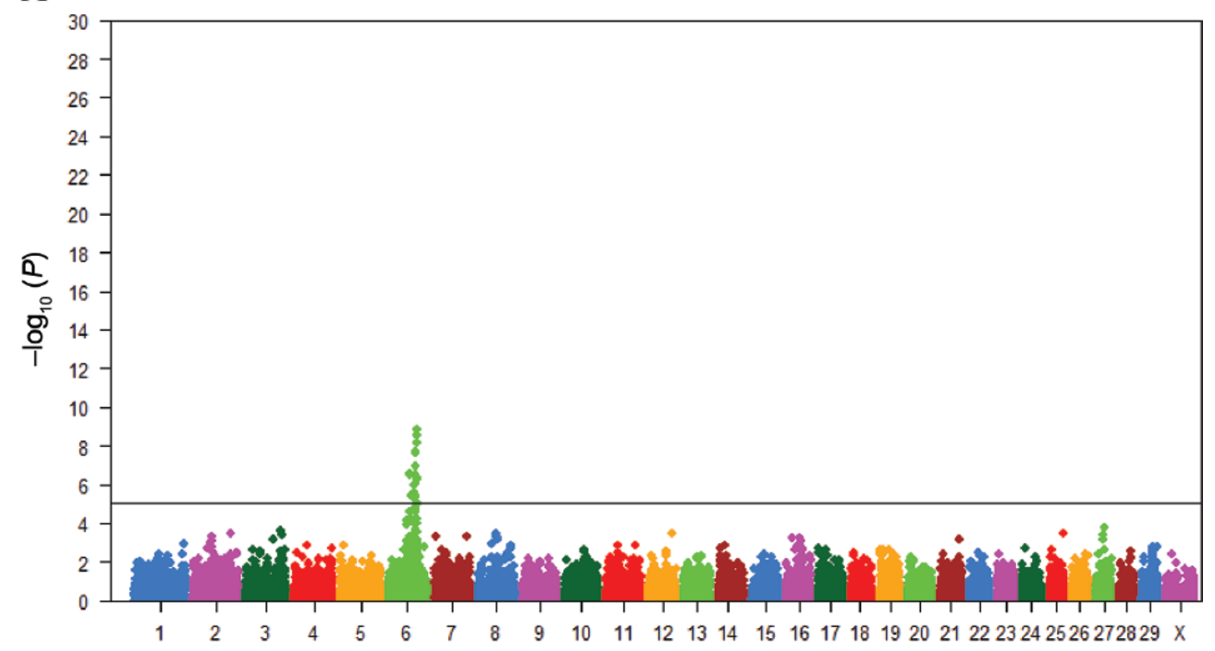

$\mathrm{B}$

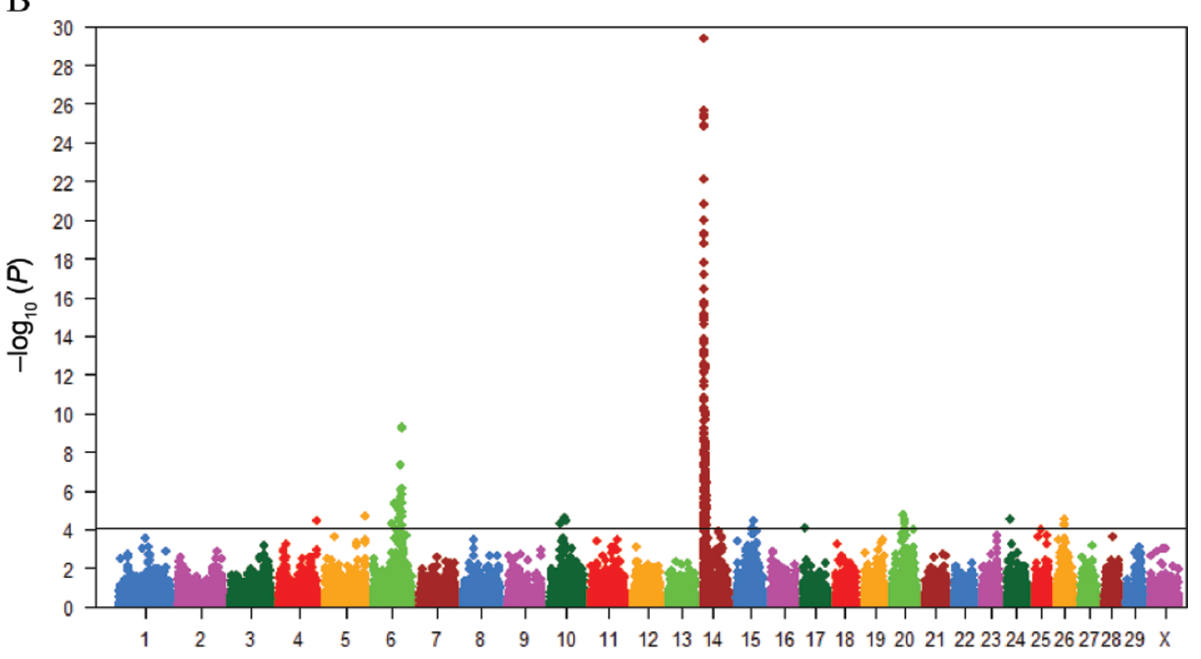

$\mathrm{C}$

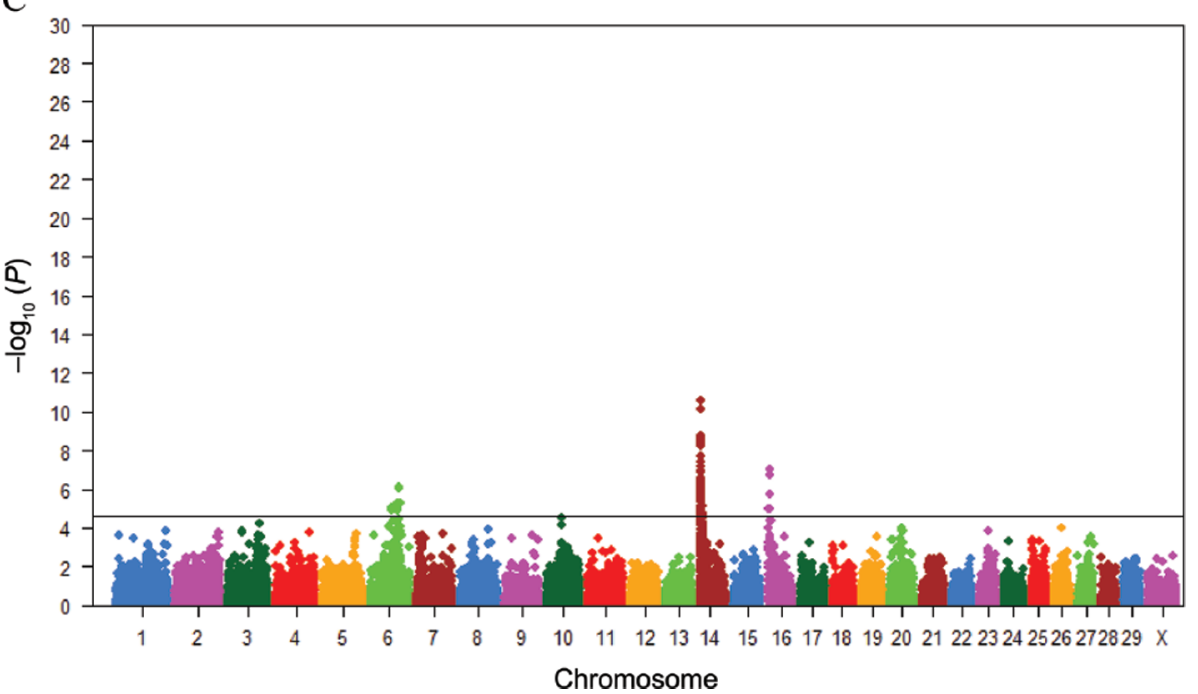

Figure 1. Manhattan plot for milk protein content in specific different lactation stages. (A) Lactation stages 1 and 2 (d 0-30), (B) lactation stages 13 and 14 (d 180-210), and (C) lactation stages 21 to 26 (d 300-390). The cut-off value for the y-axis is set at a - $\log _{10}(P$-value) of 30 . The horizontal line indicates a false discovery rate $<0.01$. 
A

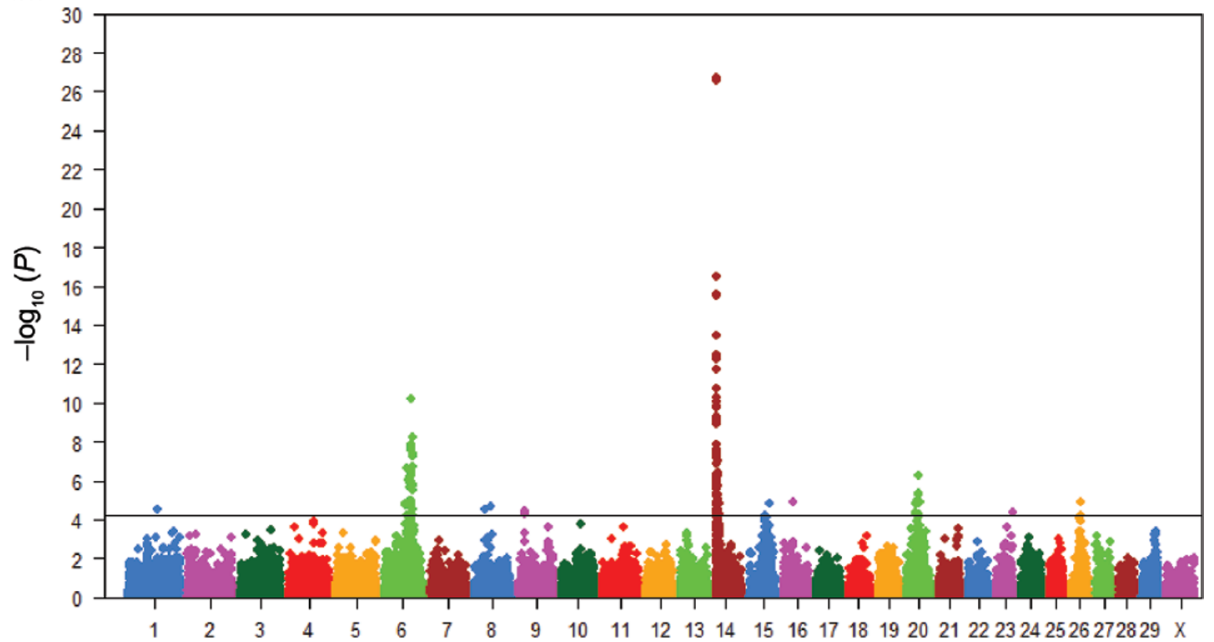

B

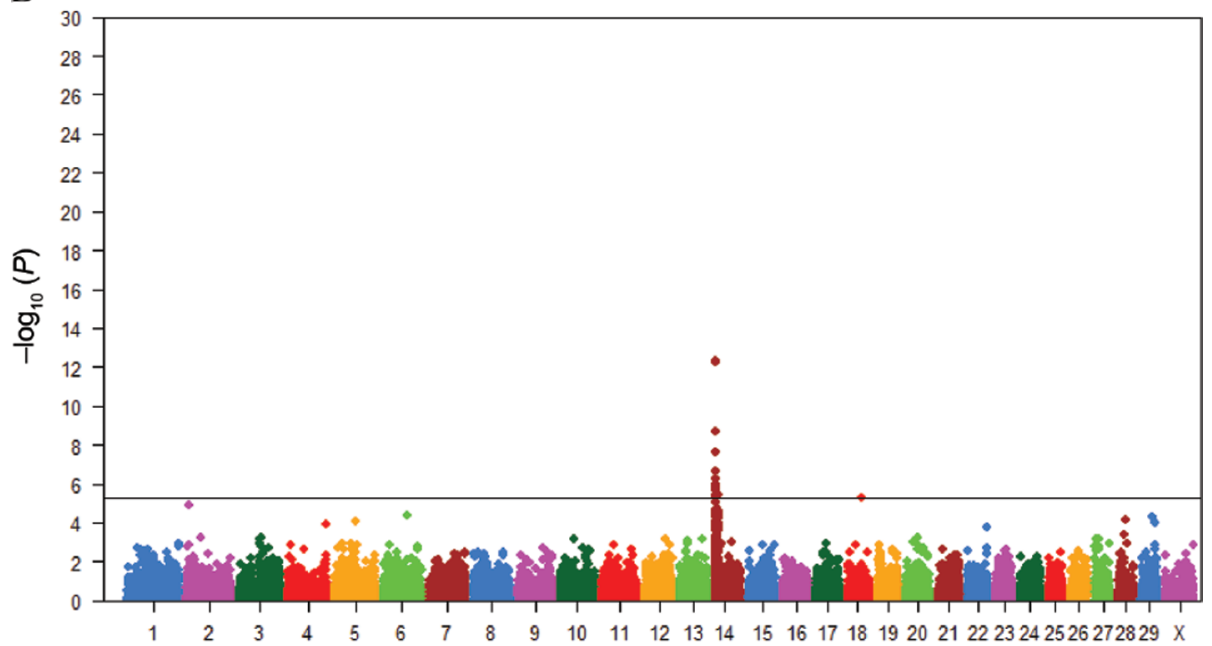

$\mathrm{C}$

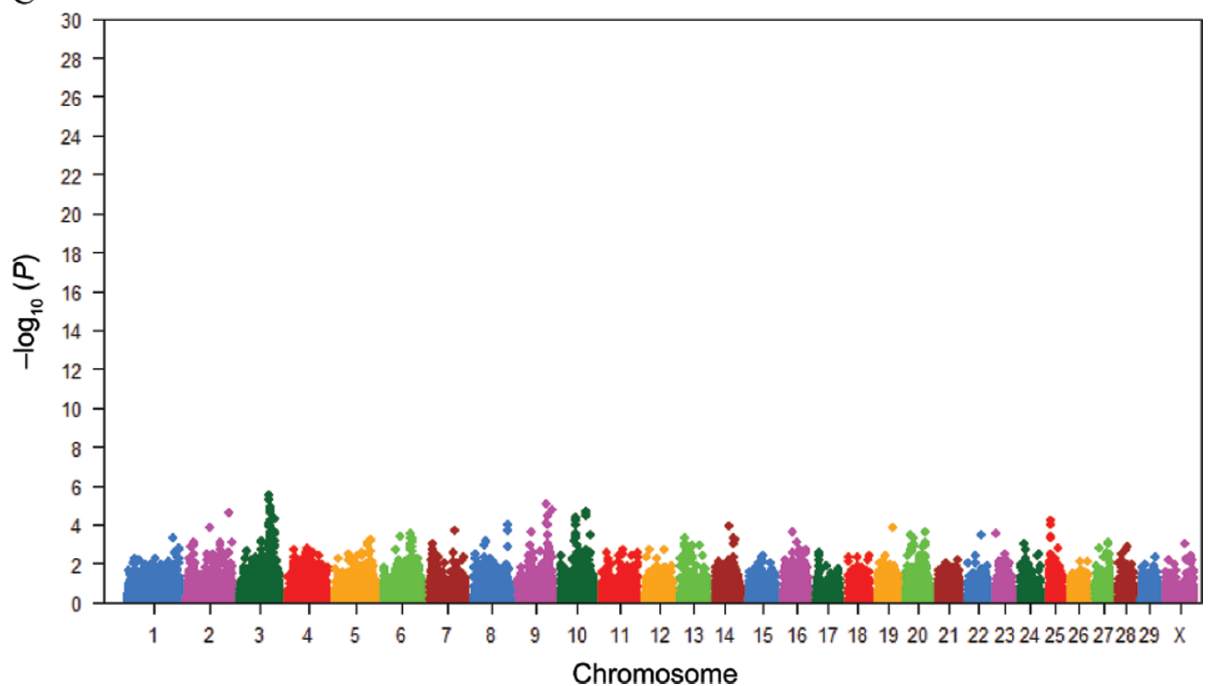

Figure 2. Manhattan plot for Wilmink lactation curve parameters fitted to milk protein test-day records: (A) Wilmink parameter a. (B) Wilmink parameter $b$. (C) Wilmink parameter $c$. The cut-off value for the y-axis is set at a $-\log _{10}(P$-value $)$ of 30 . The horizontal line indicates a false discovery rate $<0.01$. In panel $\mathrm{C}$, no threshold is indicated as none of the SNP effects were significant. 


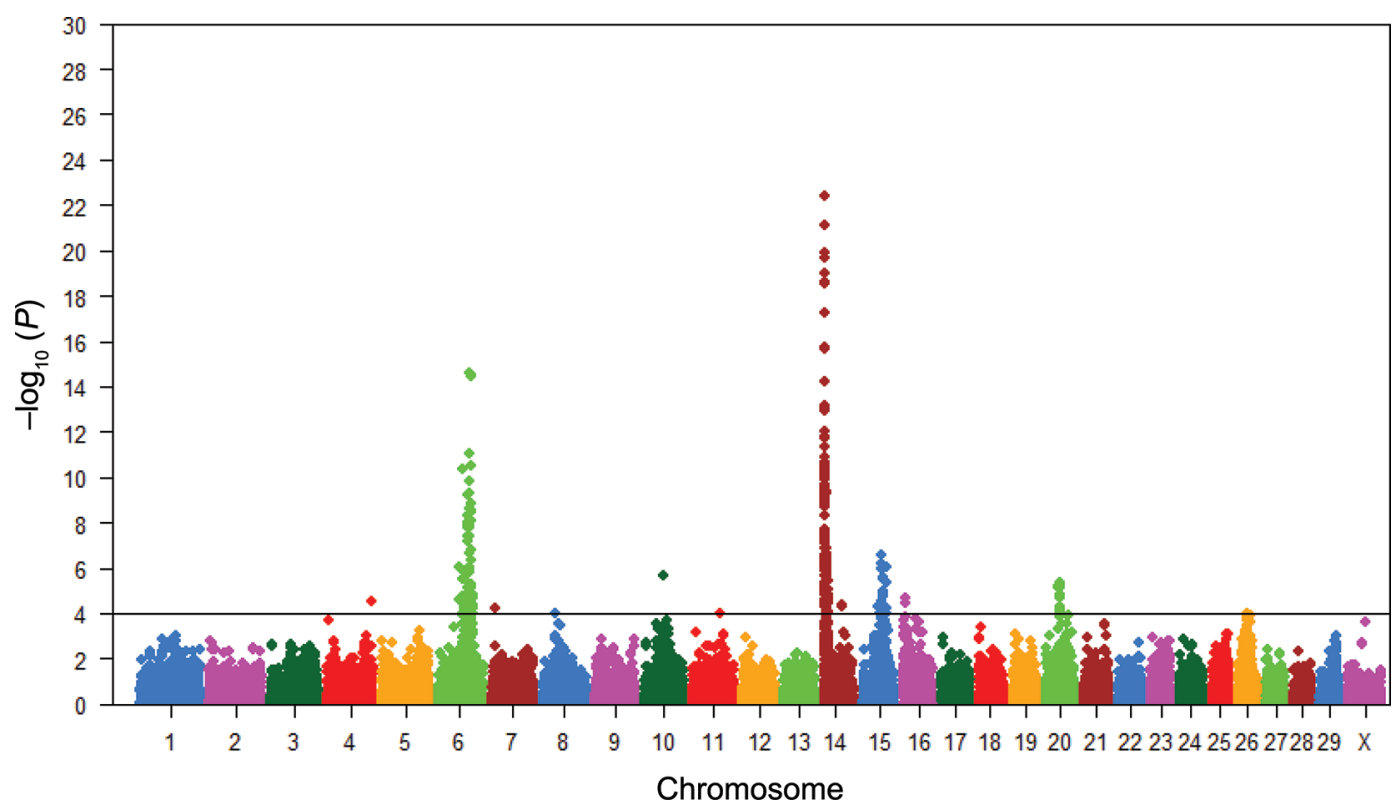

Figure 3. Manhattan plot for milk protein content based on test-day milk protein content records. The cut-off value for the y-axis is set at a $-\log _{10}(P$-value $)$ of 30 . The horizontal line indicates a false discovery rate $<0.01$.

ed effects for the $(S N P \times$ lact $)$ interaction term for the lead SNP in these chromosomal regions were obtained from model [6]. Figure 5 shows the estimated effects of the lead SNP for the 5 regions that show significant SNP by lactation stage interaction. The lead SNP on BTA 14a showed a different pattern compared with the lead SNP from the other significant regions. The lead SNP on BTA 3, 9b, 10b, and 27 in general showed no significant effects in early and mid lactation, but SNP effects became significant toward late lactation whereas the lead SNP on BTA14a showed significant effects throughout the whole lactation except for early lactation (Figure 5).

\section{Comparing Different GWAS Approaches}

On BTA 8, 9, 10, 14, 15, 16, and 26, different GWAS approaches identified different lead SNP. A 2-SNP analysis revealed that the lead SNP in region BTA $10 \mathrm{~b}$ (at 46.6 and $48.7 \mathrm{Mbp}$, Table 1) were in strong linkage disequilibrium and they detected the same QTL. Similarly, the 2 lead SNP on BTA 26 were in strong linkage disequilibrium and represented the same QTL.

Some regions only showed significant effects in one of the GWAS approaches; BTA 5, 10a, and 24 only showed significant effects in the separate GWAS for specific lactation stages; BTA 9a and 16b were only significant for Wilmink parameter $a$; BTA 18 only showed significant effects for Wilmink parameter $b$; BTA 7, 8a, and 11 were only significant in the repeatability model
[4]; and BTA 3, 9b, and 27 only showed a significant SNP by lactation stage interaction effect. The region on BTA 14a showed highly significant effects in all GWAS approaches: all lactation stages except for lactation stages 1 and 2, Wilmink parameters $a$ and $b$, the repeatability model [4], and a highly significant SNP by lactation stage interaction.

Twenty chromosomal regions on BTA $1,4,5,6,7,8 \mathrm{a}$, 8b, 9a, 10a, 10c, 11, 14b, 15a, 15b, 16a, 16b, 20, 23, 24, and 26 did not show evidence for changing effect sizes during lactation: no clear pattern in the significance for different lactation stages, no significant effects for Wilmink parameters $b$ and $c$, and no significant SNP by lactation stage interaction were detected. Five chromosomal regions on BTA 3, 9b, 10b, 14a, and 27 showed significant SNP by lactation stage interaction (model [5]), indicating that effects of these regions changed during lactation. Bos taurus autosome $10 \mathrm{~b}$ was significant in the GWAS based on data from lactation stages 21 to 26 and also showed a strong but nonsignificant GWAS signal for Wilmink parameter $c$ [Table $1,-\log _{10}(P$ value $)=4.0]$. Bos taurus autosome 14a affected both the milk protein content level (Wilmink parameter $a$ ) and the shape of the lactation curve (Wilmink parameter b). Bos taurus autosomes 3, 9b, and 27 showed a significant SNP by lactation stage interaction but did not show significant effects in any of the other GWAS analyses we performed. These 3 chromosomal regions showed a clear increase in $-\log _{10}(P$-value $)$ toward later lactation stages (Table 1, e.g., GWAS based on data 


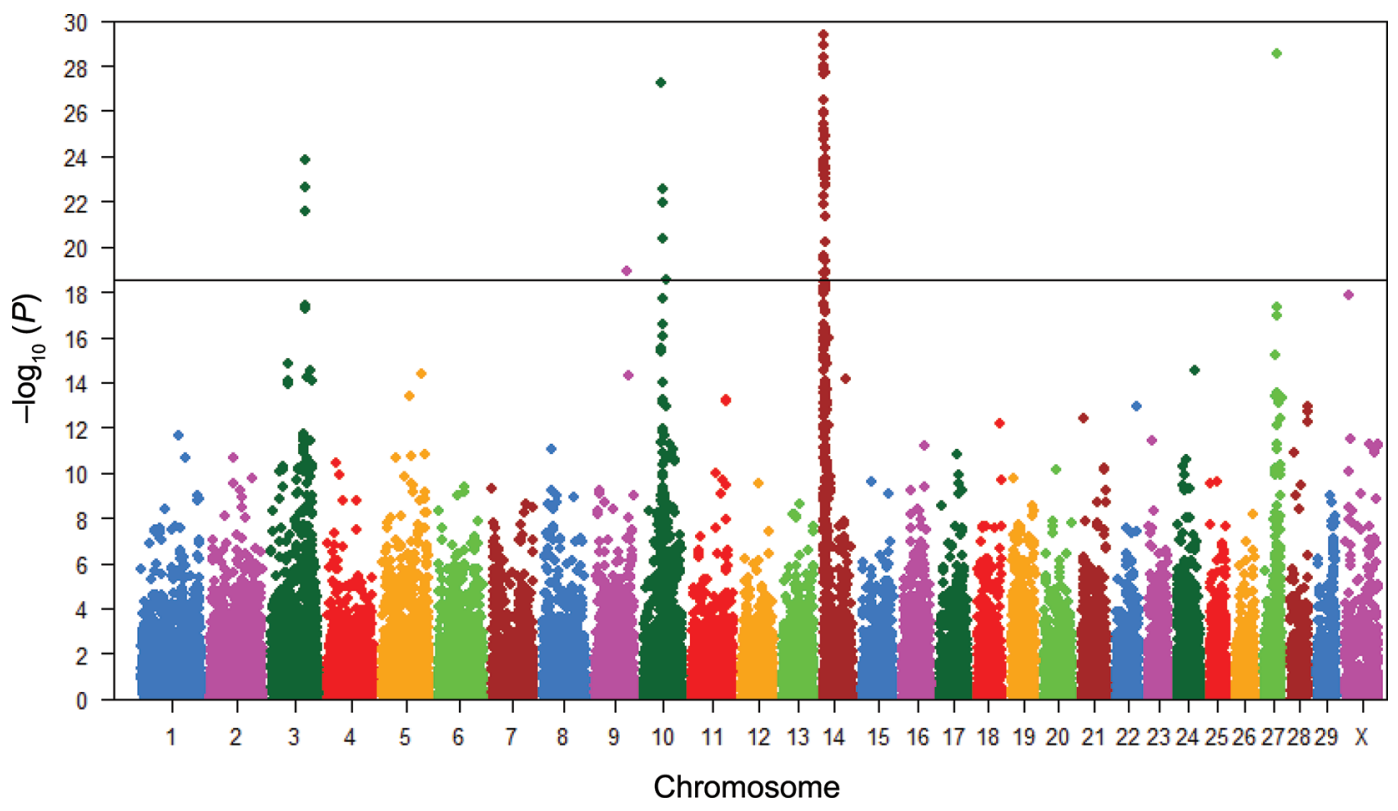

Figure 4. Manhattan plot for SNP by lactation stage interaction on milk protein content. The cut-off value for the $y$-axis is set at a $-\log _{10}(P$ value) of 30 . The horizontal line indicates the genome-wide significance threshold based on permutation $\left[-\log _{10}(P\right.$-value $\left.)=18.6\right]$.

from lactation stages 21 to 26, model [1]), although not significant. Furthermore, for Wilmink parameter $c$, the lead SNP on BTA 3 showed $-\log _{10}(P$-value $)$ of 5.5 , which is not significant at the applied threshold of FDR $<0.01$ but significant at threshold of FDR $<0.05$. Bos taurus autosome $9 \mathrm{~b}$ showed a strong but nonsignificant GWAS signal for Wilmink parameter $c$ [Table $1,-\log _{10}(P$-value $)=5.1$.

\section{DISCUSSION}

In this study we performed different GWAS using test-day milk protein content records. The objective was to specifically screen the genome for SNP whose effects change during lactation. For this purpose, 4 different approaches were performed: (1) separate GWAS for specific lactation stages; (2) GWAS for estimated Wilmink lactation curve parameters; (3) a GWAS using a repeatability model where SNP effects are assumed to be constant during lactation; and (4) a GWAS for genotype by lactation stage interaction using a repeatability model and accounting for genetic effects that change during lactation. Separate GWAS for specific lactation stages suggested that the detection power greatly differs between lactation stages and that effects of some QTL change during lactation. Many regions were detected for Wilmink parameter $a$, whereas 2 regions were detected for Wilmink parameter $b$ and no regions were detected for Wilmink parameter $c$. Twenty chromosomal regions were detected with effects on milk protein content; however, there was no evidence that their effects changed during lactation. A GWAS specifically for SNP by lactation stage interaction identified 5 regions, from which 3 were not identified based on the other GWAS approaches we performed. To determine the appropriate significance threshold for the SNP by lactation stage interaction term, permutation was used.

\section{QTL for Milk Protein Content}

In the current study regions on BTA 4, 6, 7, 8a, 10c, 11, 14a, 14b, 15a, 15b, 16a, 20, and 26 were identified using a repeatability model (model [4]) where SNP effects are assumed constant during lactation. Except for BTA 14a, we did not find evidence that effects of these regions changed during lactation (e.g., these regions were not significant for Wilmink parameters $b$ or $c$ and did not show a significant SNP by lactation stage interaction). The region on BTA 6 contains the casein gene cluster (e.g., Ferretti et al., 1990; Threadgill and Womack, 1990) and the region on BTA 20 (35.9 Mbp, Table 1$)$ is closed to the growth hormone receptor (33.9 Mbp, Btau 4.0) gene (e.g., Arranz et al., 1998; Blott et al., 2003). These 2 QTL have been shown to have large effects on milk protein content. The region on BTA 10c (51.6 Mbp, Btau 4.0) was identical to the region detected by Schopen et al. (2011) in a GWAS for milk protein composition, which was based on largely the same animals and genotypes as used in the current study. On BTA 10 (46.6 Mbp, UMD 3.1), Nayeri et 

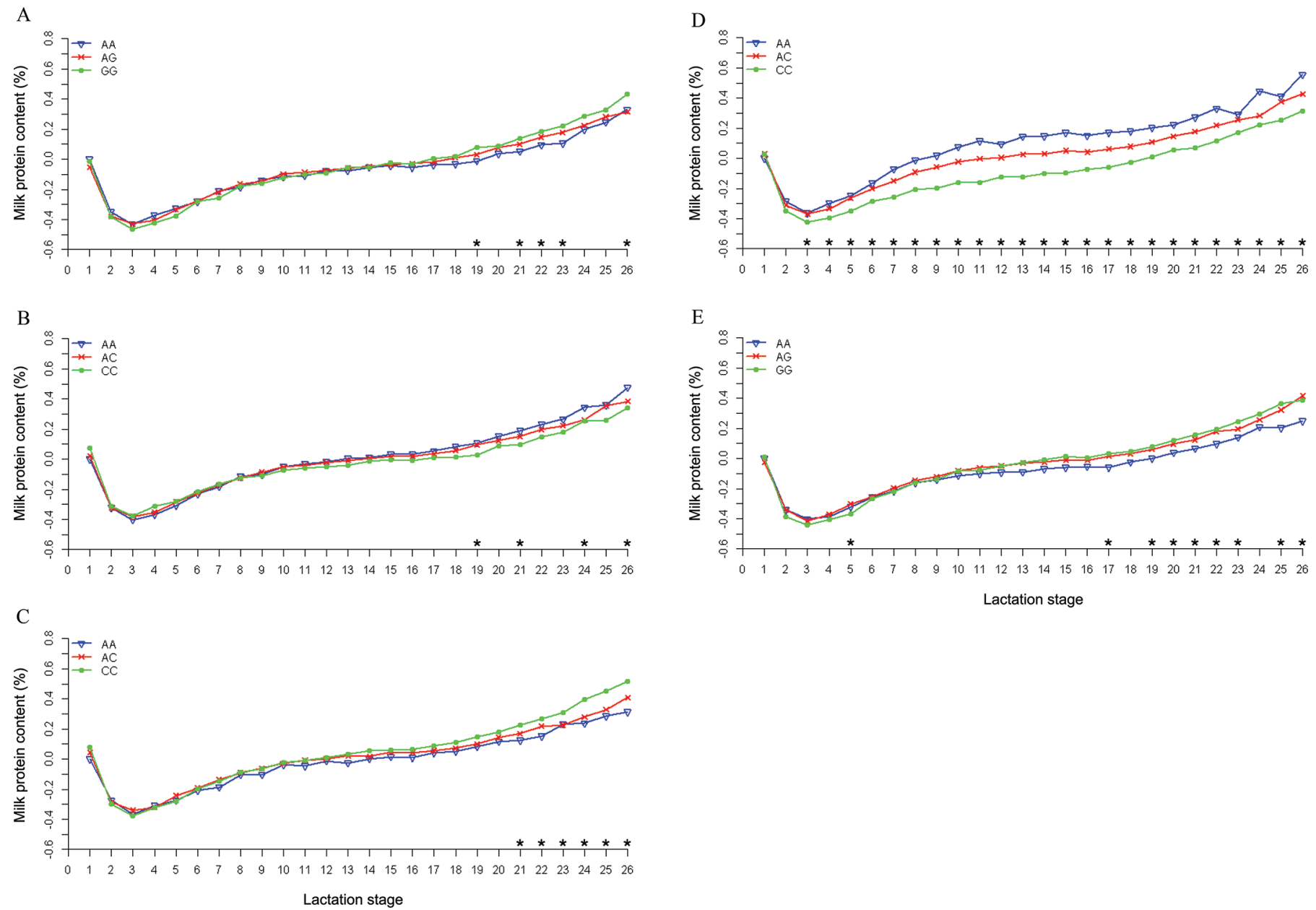

Figure 5. Effects of lead SNP genotypes that show significant SNP by lactation stage interaction during different lactation stages. (A) ULGR_rs29011303 on chromosome 3, (B) BTB-02093517 on chromosome 9, (C) ULGR_BTA-68217 on chromosome 10, (D) ULGR_SNP_ AJ318490_1b on chromosome 14, and (E) ARS-BFGL-NGS-30207 on chromosome 27. * indicates a significant $(P<0.001)$ difference between any 2 SNP genotype classes in that specific lactation stage based on a $t$-test.

al. (2016) and Pausch et al. (2017) reported significant effects on milk protein content. Significant associations for chromosomal regions on BTA 4, 14b, 15a, 15b, and $16 \mathrm{a}$ are also in agreement with results from other GWAS (e.g., Buitenhuis et al., 2016; Pausch et al., 2017; Teissier et al., 2018). The GWAS performed by Nayeri et al. (2016) and Pausch et al. (2017), which were based on large data sets, detected several chromosomal regions with effects on milk protein content that were not detected in the current study: regions on BTA 5 and 29, and a second region on BTA 6 . The reason we did not detect some of these regions might be related to power.

Regions on BTA 3, 9b, 10b, 14a, and 27 showed significant SNP by lactation stage interaction effects. The region on BTA 14a contains DGAT1, which has a major effect on several milk production traits (e.g., Grisart et al., 2002, 2004; Bovenhuis et al., 2016). Effects of $D G A T 1$ on milk production traits change during lacta- tion (Strucken et al., 2011; Szyda et al., 2014). Based on largely the same data as the current study, Bovenhuis et al. (2015) described a large DGAT1 by lactation stage interaction on milk yield, fat content, and protein content. Except for BTA 10b and 14a, the remaining 3 regions were not significant in any of the other GWAS approaches we performed. However, these regions have been associated with milk production traits in other studies. Jiang et al. (2010) reported a QTL on BTA 3 (92.8 Mbp, Btau 4.0) with effects on milk and protein yield. Strucken et al. (2012a) reported significant effects for Wilmink parameters on BTA 3 (86.6, 115.9, and $116.9 \mathrm{Mbp}$ ) for milk protein yield. These GWAS signals are close to the region on BTA 3 (93.2 Mbp, Table 1) with a significant SNP by lactation stage interaction. The region on BTA 27 (37.9 Mbp, Table 1) with a significant SNP by lactation stage interaction is closed to the 1-acylglycerol-3-phosphate O-acyltransferase 6 
(AGPAT6) gene (38.9 Mbp, Btau 4.0). The AGPAT6 is involved in milk fat synthesis and has pleiotropic effects on other milk components (Littlejohn et al., 2014) and has been shown to affect milk fat yield and fat content over the first $60 \mathrm{~d}$ of lactation (Strucken et al., 2012b). Furthermore, it has been shown that the expression of AGPAT6 in the mammary gland increases over the first $60 \mathrm{~d}$ in lactation and decreases afterward (Beigneux et al., 2006; Bionaz and Loor, 2008).

\section{Approaches to Detect QTL Whose Effects Change During Lactation}

A simple approach to find indications for genetic effects that change during lactation is to split up the data and perform separate GWAS for different parts of the lactation. However, splitting up the data does not make optimal use of all available information and does not provide a framework for significance testing of SNP whose genetic effect change during lactation. Results from separate GWAS for different parts of the lactation show large differences in number of detected chromosomal regions: in early lactation only one region significantly affected milk protein content, whereas in mid lactation up to 10 different regions were detected. This shows that the power to detect QTL greatly differs between lactation stages. The difference in the number of QTL detected in the lactation stage and the change in additive genetic variance during lactation (Supplemental Table S1; https://doi.org/10.3168/ jds.2018-15994) also suggest that the effects of QTL change during lactation.

The low QTL detection power in early lactation as compared with later lactation stages can be explained by both a lower additive genetic variance and a higher residual variance: the heritability estimate for lactation stages 1 and 2 was 0.07 , whereas for lactation stages 13 and 14 it was 0.63 (Supplemental Table S1; https:/ /doi.org/10.3168/jds.2018-15994). Separate GWAS for specific lactation stages is expected to be less powerful than GWAS based on the repeatability model as it uses approximately a 10 times smaller number of records than the repeatability model. Counterintuitively, the results obtained from the GWAS based on the smaller data set from specific lactation stages (Model [1]) and based on the repeatability model using all test-day records (Model [4]) suggest that excluding test-day records from early lactation might be a means to increase the QTL detection power. For example, the $-\log _{10}(P$ value) for the region on BTA14a containing DGAT1 based on the repeatability model [4] using all available test-day records was 33.1, whereas in the GWAS for lactation stage 13 and 14 , based on only $10 \%$ of the records, the $-\log _{10}(P$-value $)$ for $D G A T 1$ reached 47.0
(Table 1). To check if excluding records can result in a stronger GWAS signal, we performed an additional analysis using the repeatability model [4] but excluding data from lactation stages 1 to 4 . This indeed increased significance of DGAT1 from 33.1, based on all test-day records, to 54.4 when analyzed based on a smaller data set consisting of test-day records only from lactation stages 5 to 26. Difference between both homozygous DGAT1 genotypes in lactation stage 1 and 2 is -0.01 , and in lactation stage 13 and 14 this is 0.26 . In the repeatability model [4], genotypic effects are averaged over the lactation and the difference between homozygous DGAT1 genotypes is 0.18 . As QTL detection power is directly related to QTL effect size, these differences between DGAT1 genotypes are part of the explanation why excluding test-day records from early lactation is a means to increase the QTL detection power.

To detect QTL whose effects change during lactation, a 2-step approach might be used where in a first analysis lactation curves are fitted to the test-day records and in a second analysis GWAS are performed based on estimated parameters. This approach has been used in other studies (e.g., Strucken et al., 2012a; Macciotta et al., 2015) and allows detection of QTL that affect the shape of the lactation curve. In our study these analyses mainly resulted in the detection of chromosomal regions that affected the milk protein content level (Wilmink parameter $a$ ) and only 2 chromosomal regions that affected the shape of the lactation curve (Wilmink parameters b) were detected. More subtle changes in the lactation curve, which were identified based on testing for SNP by lactation stage interaction, apparently are not picked up based on GWAS for Wilmink parameters. Using models that give a more accurate description of the lactation curve might be an alternative; however, these also require estimation of more parameters (e.g., Grossman and Koops, 2003).

The GWAS for Wilmink parameters detected several chromosomal regions affecting milk protein level (Wilmink parameter $a$ ), which were not detected in the repeatability model or in most of the lactation stagespecific GWAS (regions on BTA 1, 8b, 9a, 16b, and 23). Therefore we concluded that these regions are likely false positives that might be a consequence of the 2-step approach where differences in accuracies of estimated lactation curve parameters between cows are not taken into account in the GWAS. Consequently the obtained significance of SNP effects using this 2-step approach are not correct and should be interpreted with caution.

A GWAS based on the repeatability model [4] assumes homogeneous residual variance, which is an assumption that is violated in this study, especially in early lactation. To test the sensitivity of our results to heterogeneous residual variance, we also performed a 
GWAS using phenotypes that were standardized based on the variance within each lactation stage class. This analysis did not result in the detection of chromosomal regions other than the ones reported in Table 1 (results not shown). The repeatability model assumes that SNP effects are constant throughout lactation and SNP on BTA 4, 6, 7, 8a, 10c, 11, 14b, 15a, 15b, 16a, 20, and 26 seem to follow this assumption. The assumption of constant SNP effects might lead to missing timedependent QTL effect (Lund et al., 2008; Ning et al., 2018). The effect of region on BTA 14a clearly changed during lactation, but its effect still was detected due to its large average effect. The SNP on BTA 3, 9b, 10b, and 27 , however, were not detected based on analyses using the repeatability model [4].

Testing for SNP by lactation stage interaction is an alternative approach to detect chromosomal regions whose effects change during lactation. A GWAS for SNP by lactation stage interaction identified 3 novel regions (BTA 3, 9b, and 27) that were not detected in other analyses. However, this model was not able to detect a region on BTA 16a, which showed a clear association in lactation stage 21 to $26\left[-\log _{10}(P\right.$-value $)$ $=7.0$, Table 1]. This illustrates that this approach is limited by the statistical power to detect interactions. In addition, determining the significance threshold for the interaction term needs permutation (test statistic inflation shown in Supplemental Figure S2; https://doi .org/10.3168/jds.2018-15994). To estimate significant threshold, we performed 100 permutations, which is computationally demanding.

Ning et al. (2018) used random regression to model changes in additive genetic, permanent environmental, and SNP effects on test-day milk production records. Ning et al. (2018) concluded that the proposed model can control type I errors for QTL detection and has higher power compared with a repeatability model. Theoretically, random regression modeling also would be suited for detecting QTL whose effects change during lactation. This would imply testing for the best polynomial fit of SNP effects might be computationally demanding.

\section{Biological Interpretation}

The GWAS for SNP by lactation stage interaction identify regions whose genetic effects on milk protein content change during lactation. Effects on milk protein content can be due to effects on protein yield and milk yield. Change in genetic effects are in agreement with quantitative genetic studies that show that genetic variance and genetic correlations for milk production traits change, especially during the beginning and the end of lactation. Changes of genetic effects are also confirmed based on gene expression studies (e.g., Bionaz and Loor, 2011; Wickramasinghe et al., 2012). Genetic effects of DGAT1 on BTA 14a showed a significant SNP by lactation stage interaction, which is mainly due to the lack of a DGAT1 effect in early lactation (lactation stage 1 and 2, Figure 5D). The exact mechanism behind effects of DGAT1 on milk protein synthesis remains unclear. Bovenhuis et al. (2015) indicated that most of the effects of DGAT1 on milk production traits, like milk protein content, originated from the effect on water excretion (or dilution effect) and de novo fatty acid synthesis. However, the DGAT1 polymorphism also has significant effects on the yield of different milk proteins (Bovenhuis et al., 2016). In early lactation, dairy cows might suffer a negative energy balance. During this period after calving, dairy cows mobilize body reserves to balance the energy deficit due to the dramatic increase in milk yield and the restricted feed intake (e.g., Collard et al., 2000). Bovenhuis et al. (2015) suggested that in early lactation, another DGAT enzyme, DGAT2 (Cases et al., 2001), might play a more important role than DGAT1 and this could be an explanation for the observed changes in DGAT1 effects on milk protein content.

Chromosomal regions on BTA 3, 9b, 10b, and 27 did not show significant effects on milk protein content in early and mid lactation but only in late lactation (Figure 5). In late lactation, most of the cows in our data were lactating and were pregnant. However, because of different insemination and conception dates, dairy cows were in different pregnancy stages. Pregnancy has a negative effect on milk yield as a considerable amount of the nutrients are needed for the growth and maintenance of the developing fetus (e.g., Olori et al., 1997). Gestation stage also affects fat and protein content of milk that increase as pregnancy advances (e.g., Olori et al., 1997). The mechanisms by which gestation affects milk yield and composition are mainly related to hormone-mediated partitioning of nutrients from milk production to pregnancy requirements. Furthermore, it is well established that the regulation of protein synthesis in the mammary gland is under control of hormones (Bionaz and Loor, 2011). Therefore, pregnancy might be a reason why genetic effects on milk protein content change during lactation, although the physiological mechanisms are still unknown. Associations between milk protein content and reproductive performance in dairy cows have been reported in several studies (e.g., Madouasse et al., 2010). It has been suggested that the association between milk protein content and reproductive performance is partly due to the negative energy balance in early lactation. Morton et al. (2016) indicated that factors determining milk protein content during the first $30 \mathrm{~d}$ of lactation are not identical to 
factors determining milk protein content in late lactation. Furthermore, Morton et al. (2016) suggested that milk protein content in late lactation is more important than milk protein content in early lactation for the milk protein content-reproductive performance relationship. This is in agreement with the hypothesis that pregnancy might be a reason why genetic effects on milk protein content change during lactation.

\section{CONCLUSIONS}

The current study aimed to detect genetic effects that change during lactation. For this purpose, 4 different GWAS approaches were performed for milk protein content. Separate GWAS for specific lactation stages suggested that the detection power greatly differs between lactation stages and that genetic effects of some QTL change during lactation. The GWAS for estimated Wilmink lactation curve parameters detected many QTL, but these results should be interpreted with caution because they were based on a 2-step approach. Twenty chromosomal regions were detected with effects on milk protein content; however, there was no evidence that their effects changed during lactation. Five chromosomal regions were detected whose effect on milk protein content change during lactation on BTA 3, 9b, 10b, 14a, and 27, from which BTA 3, $9 \mathrm{~b}$, and 27 were only detected in GWAS for SNP by lactation stage interaction. The performed approaches can be used to other milk production traits. Exploring QTL whose effects change during lactation is expected to elucidate the genetic and biological background of milk production.

\section{ACKNOWLEDGMENTS}

Haibo Lu is financially supported by Sino-Dutch Dairy Development Centre (Beijing, China). Yachun Wang (China Agricultural University, Beijing, China) is acknowledged for assistance in project discussion. This study uses data generated as part of the Dutch Milk Genomics Initiative project, funded by Wageningen University and Research (Wageningen, the Netherlands), the Dutch Dairy Association NZO (Zoetermeer, the Netherlands), Cooperative Cattle Improvement Organization CRV (Arnhem, the Netherlands), and the Dutch Technology Foundation STW (Utrecht, the Netherlands).

\section{REFERENCES}

Arranz, J.-J., W. Coppieters, P. Berzi, N. Cambisano, B. Grisart, L. Karim, F. Marcq, L. Moreau, C. Mezer, J. Riquet, P. Simon, P. Vanmanshoven, D. Wagenaar, and M. Georges. 1998. A QTL af- fecting milk yield and composition maps to bovine chromosome 20: A confirmation. Anim. Genet. 29:107-115.

Bastin, C., N. Gengler, and H. Soyeurt. 2011. Phenotypic and genetic variability of production traits and milk fatty acid contents across days in milk for Walloon Holstein first-parity cows. J. Dairy Sci. 94:4152-4163.

Beigneux, A. P., L. Vergnes, X. Qiao, S. Quatela, R. Davis, S. M. Watkins, R. A. Coleman, R. L. Walzem, M. Philips, K. Reue, and S. G. Young. 2006. Agpat6-a novel lipid biosynthetic gene required for triacylglycerol production in mammary epithelium. J. Lipid Res. 47:734-744.

Bionaz, M., and J. J. Loor. 2008. ACSL1, AGPAT6, FABP3, LPIN1, and SLC27A6 are the most abundant isoforms in bovine mammary tissue and their expression is affected by stage of lactation. J. Nutr. 138:1019-1024.

Bionaz, M., and J. J. Loor. 2011. Gene networks driving bovine mammary protein synthesis during the lactation cycle. Bioinform. Biol. Insights 5:83-98.

Blott, S., J. J. Kim, S. Moisio, A. Schmidt-Kuntzel, A. Cornet, P. Berzi, N. Cambisano, C. Ford, B. Grisart, D. Johnson, L. Karim, P. Simon, R. Snell, R. Spelman, J. Wong, J. Vilkki, M. Georges, F. Farnir, and W. Coppieters. 2003. Molecular dissection of a quantitative trait locus: A phenylalanine-to-tyrosine substitution in the transmembrane domain of the bovine growth hormone receptor is associated with a major effect on milk yield and composition. Genetics 163:253-266.

Bovenhuis, H., M. H. Visker, H. J. van Valenberg, A. J. Buitenhuis, and J. A. van Arendonk. 2015. Effects of the DGAT1 polymorphism on test-day milk production traits throughout lactation. J. Dairy Sci. 98:6572-6582.

Bovenhuis, H., M. H. P. W. Visker, N. A. Poulsen, J. Sehested, H. J. F. van Valenberg, J. A. M. van Arendonk, L. B. Larsen, and A. J. Buitenhuis. 2016. Effects of the diacylglycerol o-acyltransferase 1 (DGAT1) K232A polymorphism on fatty acid, protein, and mineral composition of dairy cattle milk. J. Dairy Sci. 99:3113-3123.

Buitenhuis, B., N. A. Poulsen, G. Gebreyesus, and L. B. Larsen. 2016. Estimation of genetic parameters and detection of chromosomal regions affecting the major milk proteins and their post translational modifications in Danish Holstein and Danish Jersey cattle. BMC Genet. 17:114.

Cases, S., S. J. Stone, P. Zhou, E. Yen, B. Tow, K. D. Lardizabal, T. Voelker, and R. V. Farese Jr.. 2001. Cloning of DGAT2, a second mammalian diacylglycerol acyltransferase, and related family members. J. Biol. Chem. 276:38870-38876.

Churchill, G. A., and R. W. Doerge. 1994. Empirical threshold values for quantitative trait mapping. Genetics 138:963-971.

Cole, J. B., G. R. Wiggans, L. Ma, T. S. Sonstegard, T. J. Lawlor Jr., B. A. Crooker, C. P. Van Tassell, J. Yang, S. Wang, L. K. Matukumalli, and Y. Da. 2011. Genome-wide association analysis of thirty one production, health, reproduction and body conformation traits in contemporary U.S. Holstein cows. BMC Genomics 12:408.

Collard, B. L., P. J. Boettcher, J. C. M. Dekkers, D. Petitclerc, and L. R. Schaeffer. 2000. Relationships between energy balance and health traits of dairy cattle in early lactation. J. Dairy Sci. 83:2683-2690.

Doerge, R. W., and G. A. Churchill. 1996. Permutation tests for multiple loci affecting a quantitative character. Genetics 142:285-294.

Druet, T., F. Jaffrezic, D. Boichard, and V. Ducrocq. 2003. Modeling lactation curves and estimation of genetic parameters for first lactation test-day records of French Holstein cows. J. Dairy Sci. $86: 2480-2490$.

Druet, T., F. Jaffrezic, and V. Ducrocq. 2005. Estimation of genetic parameters for test day records of dairy traits in the first three lactations. Genet. Sel. Evol. 37:257-271.

Ferretti, L., P. Leone, and V. Sgaramella. 1990. Long range restriction analysis of the bovine casein genes. Nucleic Acids Res. 18:6829 6833.

Gilmour, A. R., B. J. Gogel, B. R. Cullis, S. J. Welham, and R. Thompson. 2006. ASReml User Guide Release 1.0. 
Grisart, B., W. Coppieters, F. Farnir, L. Karim, C. Ford, P. Berzi, N. Cambisano, M. Mni, S. Reid, P. Simon, R. Spelman, M. Georges, and R. Snell. 2002. Positional candidate cloning of a QTL in dairy cattle: identification of a missense mutation in the bovine DGAT1 gene with major effect on milk yield and composition. Genome Res. 12:222-231.

Grisart, B., F. Farnir, L. Karim, N. Cambisano, J. J. Kim, A. Kvasz, M. Mni, P. Simon, J. M. Frere, W. Coppieters, and M. Georges. 2004. Genetic and functional confirmation of the causality of the DGAT1 K232A quantitative trait nucleotide in affecting milk yield and composition. Proc. Natl. Acad. Sci. USA 101:2398-2403.

Grossman, M., and W. J. Koops. 2003. Modeling extended lactation curves of dairy cattle: A biological basis for the multiphasic approach. J. Dairy Sci. 86:988-998.

Jakobsen, J. H., P. Madsen, J. Jensen, J. Pedersen, L. G. Christensen, and D. A. Sorensen. 2002. Genetic parameters for milk production and persistency for Danish Holsteins estimated in random regression models using REML. J. Dairy Sci. 85:1607-1616.

Jiang, L., J. Liu, D. Sun, P. Ma, X. Ding, Y. Yu, and Q. Zhang. 2010. Genome wide association studies for milk production traits in Chinese Holstein population. PLoS One 5:e13661.

Littlejohn, M. D., K. Tiplady, T. Lopdell, T. A. Law, A. Scott, C Harland, R. Sherlock, K. Henty, V. Obolonkin, K. Lehnert, A. Macgibbon, R. J. Spelman, S. R. Davis, and R. G. Snell. 2014. Expression variants of the lipogenic AGPAT6 gene affect diverse milk composition phenotypes in Bos taurus. PLoS One 9:e85757.

Liu, Y., X. Qin, X. Z. H. Song, H. Jiang, Y. Shen, K. J. Durbin, S. Lien, M. P. Kent, M. Sodeland, Y. Ren, L. Zhang, E. Sodergren, P. Havlak, K. C. Worley, G. M. Weinstock, and R. A. Gibbs. 2009. Bos taurus genome assembly. BMC Genomics 10:180. https://doi .org/10.1186/1471-2164-10-180.

Lund, M. S., P. Sorensen, P. Madsen, and F. Jaffrezic. 2008. Detection and modelling of time-dependent QTL in animal populations. Genet. Sel. Evol. 40:177-194.

Macciotta, N. P., G. Gaspa, L. Bomba, D. Vicario, C. Dimauro, M. Cellesi, and P. Ajmone-Marsan. 2015. Genome-wide association analysis in Italian Simmental cows for lactation curve traits using a low-density (7K) SNP panel. J. Dairy Sci. 98:8175-8185.

Madouasse, A., J. N. Huxley, W. J. Browne, A. J. Bradley, I. L. Dryden, and M. J. Green. 2010. Use of individual cow milk recording data at the start of lactation to predict the calving to conception interval. J. Dairy Sci. 93:4677-4690.

Marigorta, U. M., and G. Gibson. 2014. A simulation study of gene-byenvironment interactions in GWAS implies ample hidden effects. Front. Genet. 5:225.

Morton, J. M., M. J. Auldist, M. L. Douglas, and K. L. Macmillan. 2016. Associations between milk protein concentration at various stages of lactation and reproductive performance in dairy cows. J. Dairy Sci. 99:10044-10056.

Nayeri, S., M. Sargolzaei, M. K. Abo-Ismail, N. May, S. P. Miller, F. Schenkel, S. S. Moore, and P. Stothard. 2016. Genome-wide association for milk production and female fertility traits in Canadian dairy Holstein cattle. BMC Genet. 17:75.
Ning, C., D. Wang, X. Zheng, Q. Zhang, S. Zhang, R. Mrode, and J. F. Liu. 2018. Eigen decomposition expedites longitudinal genomewide association studies for milk production traits in Chinese Holstein. Genet. Sel. Evol. 50:12.

Olori, V. E., S. Brotherstone, W. G. Hill, and B. J. McGuirk. 1997. Effect of gestation stage on milk yield and composition in Holstein Friesian dairy cattle. Livest. Prod. Sci. 52:167-176.

Pausch, H., R. Emmerling, B. Gredler-Grandl, R. Fries, H. D. Daetwyler, and M. E. Goddard. 2017. Meta-analysis of sequence-based association studies across three cattle breeds reveals 25 QTL for fat and protein percentages in milk at nucleotide resolution. BMC Genomics 18:853.

SAS Institute Inc. 1999. SAS Procedures Guide. Version 8. SAS Institute Inc., Cary, NC.

Schopen, G. C. B., M. H. P. W. Visker, P. D. Koks, E. Mullaart, J. A M. van Arendonk, and H. Bovenhuis. 2011. Whole-genome association study for milk protein composition in dairy cattle. J. Dairy Sci. 94:3148-3158.

Storey, J. D., and R. Tibshirani. 2003. Statistical significance for genomewide studies. Proc. Natl. Acad. Sci. USA 100:9440-9445.

Strucken, E. M., R. H. Bortfeldt, D. J. de Koning, and G. A. Brockmann. 2012a. Genome-wide associations for investigating timedependent genetic effects for milk production traits in dairy cattle. Anim. Genet. 43:375-382.

Strucken, E. M., R. H. Bortfeldt, J. Tetens, G. Thaller, and G. A Brockmann. 2012b. Genetic effects and correlations between production and fertility traits and their dependency on the lactationstage in Holstein Friesians. BMC Genet. 13:108.

Strucken, E. M., D. J. de Koning, S. A. Rahmatalla, and G. A. Brockmann. 2011. Lactation curve models for estimating gene effects over a timeline. J. Dairy Sci. 94:442-449.

Szyda, J., J. Komisarek, and I. Antkowiak. 2014. Modelling effects of candidate genes on complex traits as variables over time. Anim. Genet. 45:322-328.

Teissier, M., M. P. Sanchez, M. Boussaha, A. Barbat, C. Hoze, C. Robert-Granie, and P. Croiseau. 2018. Use of meta-analyses and joint analyses to select variants in whole genome sequences for genomic evaluation: An application in milk production of French dairy cattle breeds. J. Dairy Sci. 101:3126-3139.

Threadgill, D. W., and J. E. Womack. 1990. Genomic analysis of the major bovine milk protein genes. Nucleic Acids Res. 18:6935-6942.

Voorman, A., T. Lumley, B. McKnight, and K. Rice. 2011. Behavior of QQ-plots and genomic control in studies of gene-environment interaction. PLoS One 6:e19416.

Wickramasinghe, S., G. Rincon, A. Islas-Trejo, and J. F. Medrano. 2012. Transcriptional profiling of bovine milk using RNA sequencing. BMC Genomics 13:45.

Wilmink, J. B. M. 1987. Adjustment of test-day milk, fat and protein yield for age, season and stage of lactation. Livest. Prod. Sci. 16:335-348. 